\title{
Comparative analysis for presurgical use of steroidal and nonsteroidal anti-inflammatory medication in gingivectomy procedure
}

\author{
Sumant Kumar Singh ${ }^{1}$, Amit Kumar Srivastava ${ }^{2 *}$, Manoj Kumar ${ }^{3}$, Arpita Srivastava ${ }^{4}$, Harish Tiwari ${ }^{5}$ \\ ${ }^{1}$ Assistant Professor, ${ }^{2}$ Associate Professor, ${ }^{3}$ Professor, ${ }^{4,5}$ Lecturer, ${ }^{1-3}$ Dept. of Dental Surgery, ${ }^{5}$ Dept. of Community Medicine, ${ }^{1-3,5}$ Baba \\ Raghav Das Medical College, Gorakhpur, Uttar Pradesh, ${ }^{4}$ Purvanchal Institute of Dental Sciences, Gorakhpur, Uttar Pradesh, India
}

*Corresponding Author: Amit Kumar Srivastava

Email: amit.radc@gmail.com

\begin{abstract}
Aims: The aim of this study was to evaluate the role of Dexamethasone (Steroidal anti-inflammatory drug) and Ibuprofen (Nonsteroidal anti-inflammatory drug) in controlling postoperative pain and swelling following gingivectomy procedure when administered preoperatively.

Materials and Methods: It was triple blind placebo controlled clinical trial in which total of 60 patients were randomly allocated for external bevel gingivectomy. All patients were divided in three groups as follows: In Group A: Tab Dexamethasone 4mg, Group B:Tab Ibuprofen 400mg and in Group C: Placebo tab orally given to the patients 30 minutes before gingivectomy procedure. Pain intensity were evaluated using visual analog scale(VAS) at $6 \mathrm{hr}, 12 \mathrm{hr}, 24 \mathrm{hr}$, day 2 and on day 3 postgingivectomy period and swelling scores at day 1 ,day 2 and on day 3 postgingivectomy period using visual scoring system. The data collected were statistically analysed using one way analysis of variance (ANOVA) test.

Result \& Conclusion: At $6 \mathrm{hr}$ and $12 \mathrm{hr}$ postgingivectomy period pain intensity was almost same with Group A (Dexamethasone) and Group B (Ibuprofen) and was maximum with Placebo group. At 24hr, day 2 and day 3 postgingivectomy period, the pain intensity was least with Dexamethasone group followed by Ibuprofen then Placebo group. It was found that at day 1 postgingivectomy period swelling was significantly less with Dexamethasone group followed by Ibuprofen group then Placebo group. The present study showed that Dexamethasone is better than Ibuprofen in controlling pain and edema following gingivectomy procedure.
\end{abstract}

Keywords: Steroidal anti-inflammatory drugs (SAIDs), Nonsteroidal anti-inflammatory drugs (NSAIDs), Central sensitization, Peripheral sensitization, Cyclooxygenase pathway, Phospholipase enzyme.

\section{Introduction}

Preemptive analgesia is defined as an antinociceptive treatment that prevents establishment of altered central processing of afferent input from injury. ${ }^{1,2}$ As a consequence preemptive analgesia can reduce immediate postoperative pain and also prevent the development of chronic pain by decreasing the altered central sensory response. ${ }^{3}$ Local tissue damage causing release of chemical mediators (hydroxyl ion, noradrenalin, bradykinin, histamine, potassium ion, prostaglandin, cytokines and leukotrienes) are responsible for peripheral sensitization which increase the excitability of dorsal horn neurons followed by central sensitization. Once central sensitization established, patients respond poorly to analgesics. $^{4}$ The concept of preemptive analgesia to minimize postoperative pain by preventing central sensitization even before surgery. After establishment of central sensitization due to surgical tissue damage, postoperative hyperesthesia is protracted and it takes additional time for improvement. However if preemptive analgesia provided before surgery, central sensitization suppressed and postoperative hyperesthesia does not occur. A variety of anti-inflammatory medications administered preoperatively such as nonsteroidal anti-inflammatory drugs (NSAIDs) or steroidal anti-inflammatory drugs (SAIDs) are found to reduce postoperative pain intensity. ${ }^{5}$ The NSAIDs act by blocking the cyclooxygenase (COX) pathway, producing effects on arachidonic acid metabolism and on the inhibition of synthesis of certain metabolites, such as Prostaglandins (PGs). The SAIDS defined as corticosteroids have a higher activity than NSAIDs due to blockade of A2 phospholipase enzyme, thereby reducing not only the release of PGs, but also other chemical mediators like leukotriens and thromboxanes. ${ }^{6}$ The aim of this study was to evaluate the role of Dexamethasone and Ibuprofen when administered orally 30 minutes before gingivectomy in controlling postoperative pain and swelling.

\section{Materials and Methods}

This triple blind placebo controlled clinical trial was carried out in the out patient Dept. of Periodontics, Purvanchal Institute of Dental Sciences, Gorakhpur and Dental Surgery Department, B.R.D. Medical College, Gorakhpur. All patients were explained about the study and an informed consents were obtained from them. Ethical committee clearance was obtained before starting of the study.

\section{Subject selection}

Patient with both sexes, age group ranging between 18-45 years with good general health and oral hygiene habit were selected for the study. Subject were not taken any systemic antibiotic since last 6 months before the commencement of the study. Patient with moderate to advanced periodontal destruction with suprabony pocket more than $5 \mathrm{~mm}$ in depth or gingival enlargement in which the bottom of the pocket not apical to the mucogingival junction were included in the study.

\section{Study design}

A total of 60 patients were selected for the external bevel gingivectomy. The patients were randomly divided into 
three groups. Each group had 20 patients. Group A: Tab Dexamethasone (4mg) orally, Group B: Tab Ibuprofen (400mg) orally and in Group C: Placebo drug orally administered 30 minutes before gingivectomy. A definite set of questionnaires are given to the patients to fill at $6 \mathrm{hr}, 12 \mathrm{hr}$, $24 \mathrm{hr}$, day 2 and day 3 after gingivectomy to assess the patients experience of pain and discomfort postoperatively.

\section{Presurgical consideration}

All patients were subjected to a thorough initial mouth preparation, oral hygiene instructions, scaling, root planing and polishing etc. at least one week before gingivectomy to minimize gingival inflammation so that identical clinical pictures existing in all the surgical areas.

\section{Surgical procedure}

Following administration of local anaesthesia (Lignocaine $\mathrm{HCl} 2 \%$ with Adrenalin 1:100000), pocket depth marked with the help of pocket marker facially and lingually. External bevel gingivectomy was performed as described by Goldman. ${ }^{7}$

\section{Postsurgical consideration}

Patients were under proper antibiotic coverage and advised to take 1 tab Acetaminophen (Paracetamol) 650mg as a rescue analgesic. Patients were strictly advised to take rescue analgesic only when they feel noticiable pain and can repeat the dose at every 6 hours. Patients were recalled at day1, day2 and on day 3 postoperatively. At each of recall visit oral hygiene was assessed and oral hygiene instructions were reinforced.

\section{Postoperative pain}

The visual analog scale (VAS) was used to evaluate the pain experienced by the patients. It consist of $0-10 \mathrm{~cm}$ scale with $1 \mathrm{~cm}$ graduations. The level no pain was given the position zero and the level most severe pain was given the position ten. Pain scoring: Score 0-No pain, Score1-Mild pain, Score 2-Moderate and Score 3-Severe. ${ }^{8}$

\section{Postoperative swelling}

At every postsurgical recall visit operated areas were assessed for swelling by visual scoring system. Swelling scoring: Score 0-none (No swelling), Score 1-Mild, Score 2Moderate, Score 3-Severe. ${ }^{8}$

\section{Statistical analysis}

Statistical analysis employed to compare the study results using a computer software (Epi info software). To determine the differences in the distribution of various parameters between groups one way analysis of variance (ANOVA) test were utilized. $\mathrm{P}$ value $<0.05$ was considered significant.

\section{Result}

In the present study a total of 60 patients were selected for gingivectomy. At $6 \mathrm{hr}$ and $12 \mathrm{hr}$ postgingivectomy period, the mean value of pain were almost same with Dexamethasone and Ibuprofen group and maximum with
Placebo. At 24hrs, day 2 and day 3 postgingivectomy period, the pain experience was least with Dexamethasone group followed by Ibuprofen group then Placebo group. The result was statistically insignificant in term of pain reduction in all three groups. At day 1 postgingivectomy period, the mean value for swelling in three groups $\mathrm{A}, \mathrm{B}$ and $\mathrm{C}$ were $1.50,1.95$ and 2.15 respectively. This showed that day 1 postgingivectomy period swelling was significantly less with Dexamethasone group followed by Ibuprofen group then Placebo group. At day 2 and day 3 postgingivectomy period swelling was insignificant between these three group but was least with Dexamethasone group.

\section{Discussion}

The NSAIDs and SAIDs are the anti-inflammatory drugs that are commonly used to reduce pain since long time. They inhibit the inflammatory mediators. NSAIDs act by blocking the cyclooxygenase (COX) pathway affecting the arachidonic acid metabolism, thus inhibiting synthesis of certain metabolites like Prostaglandins(PGs), on the other hand SAIDs, a corticosteroids have a higher activity than NSAIDs due to blockade of A2 phospholipase enzyme, thereby reducing not only the release of PGs but also other chemical mediators like leukotriens and thromboxanes. Abe et al in 2001 compared the preemptive analgesic effect of three groups: local anaesthesia, preoperative administration of ketamine and preoperative administration of flurbiprofen in maxillary sinus surgery under general anaesthesis. All three group showed significantly lower postoperative pain when compared to the control group. ${ }^{9}$ Simone et al observed in their study that preoperatively administered intravenous Diclofenac effectively reduces the post craniotomy headache even on the $5^{\text {th }}$ postoperative day. ${ }^{10}$ In a randomized study it was found that preemptive administration of a combination of low dose IV Ketamine with Diclofenac Sodium improved postoperative analgesia after laparoscopic cholecystectomy. Pilatti et al evaluated the preemptive and postsurgical use of Dexamethasone and Celecoxib (NSAIDs) (One our before surgery and $8 \mathrm{hr}$ after the first dose) for the control of postoperative pain found both Dexamethasone and Celecoxib were effective when used as preemptive and postoperative medication. ${ }^{11}$ The preemptive effect of a nonsteroidal COX2 inhibitor with SAID has been demonstrated in crown lengthening surgeries. Both anti-inflammatory drugs protocols presented a similar potential for pain and edema relief following periodontal surgery. ${ }^{12}$ Mehra et al 2013 compared different pharmacological regimen using SAIDs and NSAIDs and demonstrated that the NSAIDs (Ibuprofen) produced an increased reduction of pain. Patients receiving $600 \mathrm{mg}$ of Ibuprofen preemptive and postoperative for a week reported increased effectiveness in reducing PGE2 level in urine and saliva compared to Dexamethasone alone after the removal of impacted lower third molar. ${ }^{13}$ Previous research results showed that the use of SAIDs as a preemptive medication was effective in preventing pain after removal of third molar surgeries. This can be due to inhibition the phospholipase A2 enzyme by corticosteroids reduces the release of 
arachidonic acid into leukotrienes and inflammatory cells. On the other hand NSAIDs act by blocking the cyclooxygenase pathway, producing the effects on arachidonic acid metabolism and inhibition of the synthesis of certain metabolites such as prostaglandin. ${ }^{14}$ The postoperative edema was also lower with Dexamethasone compared to Ibuprofen in root coverage combined with connective tissue graft. ${ }^{15}$ Alcantara et al demonstrated that Dexamethasone control edema better than methylpredenesolone. ${ }^{16}$

Table 1: Shows postgingivectomy pain at $6 \mathrm{hr}, 12 \mathrm{hr}, 24 \mathrm{hr}$, day 2 and day 3 in Dexamethasone, Ibuprofen and Placebo groups

\begin{tabular}{|c|c|c|c|c|}
\hline \multirow[t]{2}{*}{ Groups } & & \multicolumn{3}{|c|}{ Post operative pain at 6 hour postgingivectomy } \\
\hline & $\mathrm{N}$ & Mean & Std. Deviation & Significance \\
\hline Group A (Dexamethasone) & 20 & 1.8 & 0.41 & \multirow[t]{3}{*}{$>0.05$} \\
\hline Group B (Ibuprofen) & 20 & 1.85 & 0.37 & \\
\hline \multirow[t]{3}{*}{ Group C (Placebo) } & 20 & 2.05 & 0.40 & \\
\hline & & \multicolumn{3}{|c|}{ Post operative pain at 12 hour postgingivectomy } \\
\hline & $\mathrm{N}$ & Mean & Std. Deviation & Significance \\
\hline Group A (Dexamethasone) & 20 & 1.6 & 0.60 & \multirow[t]{3}{*}{$>0.05$} \\
\hline Group B (Ibuprofen) & 20 & 1.6 & 0.60 & \\
\hline \multirow[t]{3}{*}{ Group C (Placebo) } & 20 & 1.85 & 0.37 & \\
\hline & & \multicolumn{3}{|c|}{ Post operative pain at 24 hour postgingivectomy } \\
\hline & $\mathrm{N}$ & Mean & Std. Deviation & Significance \\
\hline GroupA (Dexamethasone) & 20 & 1.25 & 0.63 & $>0.05$ \\
\hline Group B (Ibuprofen) & 20 & 1.40 & 0.50 & \\
\hline \multirow[t]{3}{*}{ Group C (Placebo) } & 20 & 1.50 & 0.61 & \\
\hline & & \multicolumn{3}{|c|}{ Post operative pain at day 2 postgingivectomy } \\
\hline & $\mathrm{N}$ & Mean & Std. Deviation & Significance \\
\hline Group A (Dexamethasone) & 20 & 0.55 & 0.51 & $>0.05$ \\
\hline Group B (Ibuprofen) & 20 & 0.90 & 0.64 & \\
\hline \multirow[t]{3}{*}{ Group C (Placebo) } & 20 & 1.05 & 0.60 & \\
\hline & & \multicolumn{3}{|c|}{ Post operative pain at day 3 postgingivectomy } \\
\hline & $\mathrm{N}$ & Mean & Std. Deviation & Significance \\
\hline Group A (Dexamethasone) & 20 & 0.30 & 0.47 & \multirow[t]{3}{*}{$>0.05$} \\
\hline Group B (Ibuprofen) & 20 & 0.45 & 0.51 & \\
\hline Group C (Placebo) & 20 & 0.50 & 0.51 & \\
\hline
\end{tabular}

Table 2: Shows postgingivectomy swelling at day 1, day 2 and day 3 in Dexamethasone, Ibuprofen and Placebo groups

\begin{tabular}{|c|c|c|c|c|}
\hline \multirow[t]{2}{*}{ Groups } & & \multicolumn{3}{|c|}{ Post operative swelling at day 1 postgingivectomy } \\
\hline & $\mathrm{N}$ & Mean & Std. Deviation & Significance \\
\hline Group A (Dexamethasone) & 20 & 1.55 & 0.44 & \multirow[t]{3}{*}{$<0.05$} \\
\hline Group B (Ibuprofen) & 20 & 1.95 & 0.31 & \\
\hline \multirow{3}{*}{ Group C (Placebo) } & 20 & 2.15 & 0.22 & \\
\hline & & \multicolumn{3}{|c|}{ Post operative swelling at day 2 postgingivectomy } \\
\hline & $\mathrm{N}$ & Mean & Std. Deviation & Significance \\
\hline Group A (Dexamethasone) & 20 & 1.75 & 0.44 & \multirow[t]{3}{*}{$>0.05$} \\
\hline Group B (Ibuprofen) & 20 & 1.65 & 0.49 & \\
\hline \multirow[t]{3}{*}{ Group C (Placebo) } & 20 & 1.65 & 0.49 & \\
\hline & & \multicolumn{3}{|c|}{ Post operative swelling at day 3 postgingivectomy } \\
\hline & $\mathrm{N}$ & Mean & Std. Deviation & Significance \\
\hline Group A (Dexamethasone) & 20 & 0.80 & 0.52 & \multirow[t]{3}{*}{$>0.05$} \\
\hline Group B (Ibuprofen) & 20 & 1.20 & 0.61 & \\
\hline Group C (Placebo) & 20 & 1.35 & 0.59 & \\
\hline
\end{tabular}




\section{Conclusion}

Both the SAID (Dexamethasone) and NSAID (Ibuprofen) drugs presented a positive final outcome in the control of inflammatory signs and symptoms during the postgingivectomy period. Overall results showed that the use of Dexamethasone is superior compared to Ibuprofen then placebo when used as preemptive medication in controlling pain and swelling after gingivectomy procedure.

\section{Source of funding}

None.

\section{Conflict of interest}

None.

\section{References}

1. Nageswar. Comma incision for impacted third molar. J Oral Maxillofac Surg 2002;60:1506-9.

2. Igor K. Preemptive analgesia. Anaesthesiol 2000;93:1138-43.

3. Forsgren H, Heimdahl A, Johansson B, Krekmanov L. Effect of application of cold dressings on post operative course in oral surgery. Int J Oral Surg 1985;14:223-8.

4. Woolf CJ. Chung MS. Preemptive analgesia- treating postoperative pain by preventing the establishment of central sensitization. Anesth Analg 1993;77:362-79.

5. American Academy of Periodontology. Consensus report on mucogingival therapy. Proceedings of the World Workshop in periodontics. Ann Periodontal 1996;1:702-6.

6. Laureano-Filho JR, Maurete PE, Allais M, Cotinho M, Fernandes C. Clinical comparative study of effectiveness of two dosages of Dexamethasone to control postoperative swelling, trimus and pain after the surgical extraction of mandibular impacted third molars. Med Oral Patol Oral Cir Bucal 2008;13:129-32.

7. Goldman H.M Gingivectomy. Oral Surg Oral Med Oral Pathol 1951;4:1136-57.

8. N Thuaksuban. A comparative study of postoperative pain using CO2 laser and scalpel in maxillofacial soft tissue surgery. Int Congress Series 2003;1248:377-81.

9. Abe K. Study on alleviation of postoperative pain in oral and maxillofacial surgery under general anaesthesia. JJOM 2001;47:225-31.
10. Simone JL, Jarge WA. Comparative analysis of preemptive analgesic effect of dexamethasone and diclofenac following third molar surgery. Braz Oral Res 2013;27:266-71.

11. Pellati GL. The use of celecoxib and dexamethasone for the prevention and control of postoperative pain after periodontal surgery. J Periodontol 2006;77:1809-14.

12. Peres MF. Steroidal and non-steroidal cyclooxygenase 2 inhibitor anti-inflammatory drug as preemptive medication in patient undergoing periodontal surgery. Braz Dent $J$ 2012;23:621-8

13. Mehra P, Reebye U. Efficacy of anti-inflammatory drugs in third molar surgery: a randomized clinical trial. Int J Oral Maxillofac Surg 2013;42:835-42.

14. Czock D, Keller F. Pharmacokinetics and pharmacodynamics of systematically administered glucocorticoids. Cloin Pharmacokinet 2005;44:61-98.

15. Ana PO, Rafaela M, Reneto C. Preemptive and postoperative medication protocol for root coverage combined with connective tissue graft. Braz Dent J 2018;29(2):23-9.

16. Alcantra CE, Falci SG. Preemptive effect of dexamethasone and methylprednisolone on pain, swelling and trismus after third molar surgery: A split mouth randomized triple blind clinical trial. Int J Oral Maxillofac Surg 2014;43:93-8.

How to cite this article: Singh SK, Srivastava AK, Kumar M, Srivastava A, Tiwari H. Comparative analysis for presurgical use of steroidal and nonsteroidal antiinflammatory medication in gingivectomy procedure. Int $J$ Oral Health Dent 2019;5(4):208-11. 